\title{
Disaster and restoration governance of the 2014 Kaohsiung gas explosion
}

\author{
J. W. Wu \& M. H. Cheng \\ National Sun Yat-sen University, Taiwan, ROC
}

\begin{abstract}
Although the government took quick emergency action following the Kaohsiung gas explosion of 31 July 2014, there were still thirty-two persons (including six fire-fighters) killed and more than three hundred victims wounded. Because the explosion was caused by leaking industrial underground propene pipelines, it also seriously hurt the Kaohsiung energy supply system and economic development. It was very urgent for the government to carry out post-disaster restoration for the ripped-up roads and the damaged buildings. This paper examines the problems of the above incidents, relates the experiences of the rescue and restoration to rebuild residents' lives, and suggests an approach of integrated governance. This research provides the central and local government with some important suggestions to deliver appropriate sustainable energy policies and reduce the environmental risk. Keywords: Kaohsiung gas explosion, post-disaster restoration, integrated governance.
\end{abstract}

\section{Introduction}

The worst gas explosion in Taiwan blasted in Kaohsiung city on 31 July 2014, and although the local government quickly took emergency steps to for rescue and relief, thirty-two persons (including six firefighters) were killed and more than three hundred victims were injured. However, it was not the first and would not be the last gas explosion in Kaohsiung, as there were other kinds of gas explosions even during the restoration period, and the dangers of gas explosion should be prevented and protected against.

Besides the gas explosion, this disaster was combined with heavy rains and flooding in the days following the explosions, and a serious epidemic outbreak of dengue fever occurred like never before in Kaohsiung, so a composite of difficult 
problems occurred in the destroyed district. Consequently, it is urgent that the above problems be deeply examined and exact useful solutions be explored and established.

Kaohsiung is a harbor city, and there are many heavy industrial production plants in this city, including steel, ships and fossil fuels manufacturing plants. Industry values weights $74.52 \%$ of GDP in Kaohsiung, and about three-hundred thousand people work for the petrochemical industry. Thus, our country and Kaohsiung city are highly dependent on the fossil fuel industry. The current big gas explosions were caused by management flaws of propylene transportation. These explosions destroyed the life of citizens, the traffic system, industrial processing, and even political issues. Furthermore, the energy supply system, economic development and sustainability were heavily affected, and these urgent responsibilities, disaster management and restoration issues are to be presented in this study.

Additionally, this paper reviews some important references of urban environment crisis management. It uses the time series method and integrated governance to examine the Kaohsiung gas explosion events and analyze similar international gas explosion events, in an attempt to provide lessons learnt from the above disaster events and give useful advice about the energy crisis system and sustainable development.

\section{Kaohsiung gas explosion events}

\subsection{Kaohsiung city}

Kaohsiung city has a 2,946 square kilometer area and 2.78 million people with various characteristics and traditional races cultures. The main goals of city government are to construct a resilient, safe and people-first city, in order to provide citizens with a better living environment. In creating the most urgent challenges of climate change, more typhoons with heavy rainfalls have been hitting Kaohsiung, and local authorities have paid much more attention to water management strategies of water conservation, flood detention and flood drainage.

\subsection{Dangerous explosion causes}

However, Kaohsiung also is an industrial city and near a very busy harbor, and there are many heavy industrial production plants in this city and the harbor, including important steel, ship-building and fossil fuel manufacturing plants. Because the industrial production plants are located all around the city, in order to supply and transport fossil fuels, the convey tank trucks originally used the city road network. So for safety, this system of fossil fuel delivery was changed to an underground pipeline system during the 1970s, but these pipelines now even go through all the residential living zones and commercial districts in the city. In fact, central and local governments have not properly controlled or managed the 
underground pipelines, and the companies owning such pipelines have not maintained the pipelines either. Accordingly, gas explosion events have occurred many times.

\subsection{Kaohsiung gas explosions}

It was not the first and only time during the 2014 Kaohsiung gas explosion that underground gas pipelines had erupted, because other kinds of gas blasts had occurred even during the following restoration period, so the dangers of recurring gas explosions should be prevented and minimized immediately. This paper retrieves information from the Wikipedia web site [1], Kaohsiung City Government web site [2], and uses the history time series method to analyze the events as per the following paragraphs.

\subsubsection{Kaohsiung gas explosion in 1997}

On 13 September 1997, a large Kaohsiung gas explosion occurred. The underground fossil fuels pipeline of oil refinery CPC Corporation was destroyed at Cianjhen district, then as the fossil fuels leaked out, the gas exploded just as the fire-fighters had come to the site, resulting in eleven persons (including two firefighters) killed and seventeen victims injured.

\subsubsection{Kaohsiung gas explosion in $\mathbf{2 0 1 4}$}

On 31 July 2014, more explosions occurred at 11:57 p.m. on Yisin Road, Ersheng Road, Sanduo Road and Guanghua Road nearby the Kaohsiung City Government Hall. About three hours prior to the explosions, it was reported that a smell of gas accompanied with white smoke was coming out of manholes near Kaisyuan 3rd Road and Ersheng 1st Road earlier at 8:46 p.m., but the rescue authorities could not judge what the gas was; they just could use water to extinguish the smoke as usual.

But fireballs were then reported being seen soaring into the sky and it was estimated that the flames reached 15 stories high. The blasts ripped up about 6 kilometers of main roads, and then trapped and overturned many cars and fire trucks. The explosions reportedly blew cars and motorcycles high up in the air; some vehicles and victims were later found on the rooftops of buildings three or four stories high.

Later on, the Premier of the central government (The Executive Yuan) stated that there had been at least five blasts around the city. The blasts cut gas supplies to 23,600 households, electricity to 12,000 households, and water to 8,000 households.

Accurately, these explosions were caused by a propene leak, and the firefighters could not extinguish the fires with water. Emergency workers had to wait until the gas had burnt away after the supply was shut down. The affected pipelines were those used for gas delivery to the petrochemical factory LCY Chemical Corp, and were designed and constructed by the government-owned CPC Corporation, which construction had been completed in 1994. However, the pipelines had not been properly inspected for 24 years. 


\subsubsection{One other gas explosion}

Another gas explosion happened again, just 45 days after the worst 2014 Kaohsiung gas explosion. As Kaohsiung Rapid Transit Authority personnel were reconstructing the main channel engineering, although they found some thick and odorous smells, but could not detect the sources, types and concentrations of the gas, thereby trying to seal off the source. They still forced the workers to wear gas masks and enter the tunnel construction, and then later on, a benzene gas explosion occurred.

\subsubsection{Another construction explosion}

As restoration works were underway, there was still another flameout and unknown gas explosion again on 23 October 2014, just 53 days after the first explosion. When the Kaohsiung Public Works Bureau reconstructed the main roads engineering, the contents of the concrete used had some easy fire-causing gas materials. Then, the city government had to stop all the restoration works and withdraw the endangered residents. Finally, the local government only blamed the reconstruction contractor as being the one who should take responsibility for this accident.

\subsubsection{Composite problems}

Besides the gas explosions, the disasters were also combined with heavy rains and flooding in the days after the explosions, and along with the serious disease epidemic of dengue fever, a composite of difficult problems had occurred in the destroyed district. Therefore, it is highly urgent to deeply examine the above problems and discover exact useful solutions.

\section{Literature review}

Shaluf [3] stated that disasters could be categorized into natural, man-made, and hybrid types. Natural disasters include flooding, hurricanes, earthquakes and tsunamis. Man-made disasters include fire, transportation accidents, radiological contamination, and war. The hybrid types combine both natural and man-made disasters.

Many environment crises and disasters have taken place all over the world, for example the Indian Ocean Tsunami, Hurricane Katrina, Hurricane Hugo, Earthquake 921, the Morakot typhoon in Taiwan. And these disasters cause tremendous destruction to all countries and people, especially in urban areas. Accordingly, it is necessary to quickly examine and review the reasons, and carry out environment crisis management.

As to the gas explosions, besides the 2014 Kaohsiung gas explosion, there have been some gas explosion accidents all over the world, for example, the Guadalajara explosions in 1992, and the San Bruno pipeline explosion in 2010. These accidents are other important environmental and energy crisis to cities, but in general, they are often neglected or thought to be the toughest things to handle. Therefore, this paper provides the experiences and lessons for the authorities to take urgent action to prevent and control such the gas explosion disasters. 


\subsection{Environment crisis management}

In general, environment crisis management includes four stages: prevention, preparation, response and recovery. And risk management aims to lower the threats from known hazards. Keeney [4] stated a sound approach to risk requires both good science and good judgment.

Klein and Petley [5] determined that risk management includes three phases: risk identification, risk estimation and risk evaluation. And the reduction of risk should go through pre-disaster protection activities (risk assessment, mitigation preparedness, and emergent plans) and post-disaster recovery activities (relief, rehabilitation, reconstruction, learning review).

Ahrens and Rudolph [6] identified institutional failure as the root cause for underdevelopment and susceptibility to disasters, and explored their interdependent relationship. Only if a country's governance structure enables the implementation and enforcement of public policies conducive to a country's economic and social development can sustainable livelihoods be achieved and susceptibility to disasters be reduced. The key features of a governance structure are accountability, participation, predictability and transparency that foster development and support risk reduction.

\subsection{Explosion protection}

Heinrich and Groh [7] outlined Explosion protection:

In general, an explosion is an exothermic chemical reaction between two components. A well-known example is the reaction between the oxygen content of the atmospheric air and a combustible substance like petrol. The fundamental rule of the primary type of explosion protection: the existence of hazardous fuelair mixtures, shall be prevented by an artificial or natural ventilation of plant installations and/or an equivalent tightness of manufacturing equipment.

\subsection{Disaster prevention and management}

In general, the goal of disaster risk and management is to reduce, minimize, or eliminate damage and loss resulting from hazardous events.

Eziyi Offia Ibem [8] identified a number of critical factors, including inadequate housing and infrastructure, disaster education, institutional failures.

\subsection{Auditing recovery activities}

Labadie [9] found that the recovery and reconstruction efforts could help to mitigate possible future disaster effects by making the community more sustainable and more survivable, although auditing is still necessary for postdisaster recovery and reconstruction activities by applying the processes of performance to identify risks and controls, set measurable targets, and assess the sustainability and survivability of the recovery goals. 
Howes [10] illustrated the insurance claim issues and lessons from the disaster of the Lewes flood: having adequate insurance and a written disaster plan, keeping accurate records and statistics, and dealing with recovery works with professionals who understand the jargon.

\subsection{Disaster governance}

Geale [11] stated that the cardinal virtues of disaster response are prudence, courage, justice, stewardship, vigilance, resilience, self-effacing charity and communication. For ongoing work in disaster management, these eight virtues will help to ensure that disaster situations are managed in an ethical manner that respects the rights and privileges of all those involved.

Tun Lin Moe Pairote Pathranarakul [12] provided an integrated approach to natural disaster management about the public project management, and revealed its critical success factors: the country master plan for natural disaster management including prediction, warning, mitigation and preparedness, responsible governmental authority, clear line of authority, effective collaboration among institutions in different levels, encouragement for participation of local and international NGOs, education and knowledge for tsunami in potential disaster effected communities, and information management or database system.

\subsection{Restoration governance}

Baroudi and Rapp [13] studied the stakeholder management in disaster restoration projects and confirmed that disaster restoration projects contain significant stakeholder issues and challenges. In addition, the disaster restoration projects have their own unique identity; these are different from conventional construction.

\subsection{Summary}

Many environment crises and disasters have taken place all over the world, but from the above review, few studies illustrate the depth of the disaster and restoration problem like the Kaohsiung gas explosion in 2014.

Besides, the disaster of Kaohsiung gas explosions was also combined with heavy rains and flooding in the days after the explosions, and a serious epidemic of dengue fever never before seen in Kaohsiung, so the composite difficult problems almost destroyed the district. Therefore, it is highly urgent to deeply examine the multifaceted problems and find out the exactly useful solutions. Then, this paper provides the approach of disaster and restoration governance, and gives these experiences and lessons to the world. 


\section{Research design}

\subsection{Research problems}

According to the above analysis of international and Kaohsiung gas explosion events combined with the attendant heavy rains and flooding in the days following the explosions, along with the epidemic of dengue fever, many composite difficult problems arose. Besides, Kaohsiung is a heavy-industrial city, and the economic development and energy supply chains are vital to Kaohsiung and Taiwan.

Theoretically speaking, for the Kaohsiung gas explosion events, a so-called normal accident, we may apply the theory of path dependence to analyze the institutional failure of these matters. In order to deal with these problems, both the disaster and restoration works require the approach of integrated governance. This paper examines the problems of the above incidents, relates the experiences of the rescue and restoration to rebuild residents' lives, and suggests an approach of integrated governance.

\subsection{Research method}

According to the theory of environment crisis management, this paper divides the disaster events period into four stages: prevention, preparation, response and recovery to analyze these problems, then identifies and assesses the pre-disaster explosion protection (risk assessment, mitigation preparedness, emergent plans) and post- disaster recovery (relief, rehabilitation, reconstruction, learning review) activities by the approach of integrated governance with the key features accountability, participation, predictability and transparency. Finally, it is necessary to apply an auditing system to make sure the recovery and reconstruction activities actually have synergistic performance. Then, it includes the drawing up of experiences and lessons from the disaster of the Kaohsiung gas explosions.

\section{Research results}

\subsection{Pre-disaster governance}

\subsubsection{Pre-disaster process analyses}

Tracking back along the history process of the Kaohsiung gas explosion on 31 July 2014, it was found that the initial leaked gas and white smoke came out of manholes in the Cianjhen District at 8:46 at night, and the first explosion occurred on Yisin Road, Ersheng Road, Sanduo Road and Guanghua Road at 11:57 p.m. that night. Then, about 6 kilometers of road length, many buildings, and vehicles were destroyed with people killed and injured [1].

The three hours before the explosion incident occurred were most important, but the fire-fighters from Kaohsiung City could not judge accurately what the gas 
was, and all they could just do was to try to extinguish the smog gas by spraying water as usual, while nearby dwelling residents were not even notified to escape away from the dangerous sites.

After the explosions, the authorities investigated and found that the leaking 4-inch propene pipelines had not been properly inspected for twenty-four years.

And it was found that the LCY company piping system used to transport propene from one of its suppliers began to show pressure abnormally, but the Terminal and Distribution Corporation that transported LCY's petrochemicals through the pipes did not shut the delivering controllers down, so the propene had kept on releasing into the surrounding infrastructure until the explosions took place that night.

\subsubsection{Discussion and suggestions}

5.1.2.1 Accountability This paper finds that the local and central governments did not have enough professional knowledge and skills to handle the gas explosions disaster well, and could not control the important three hours before the explosion incident had happened. In addition, the governmental bodies should take responsibility for such work of disaster prevention.

5.1.2.2 Participation The governments, both local and national, must fully cooperate with all the petrochemical companies and the public to review a comprehensive inventory of the city's underground petrochemical pipelines, and require the companies to provide a more precise location of the pipeline in 3dimensional image diagrams.

5.1.2.3 Predictability The authorities did not even have a thorough emergency plan to deal with gas explosion disasters; still, they had gained much experience from international and domestic gas explosion disasters e.g. the Guadalajara explosions in 1992 and the Kaohsiung gas explosion in 1997. The authorities should draw up petrochemical pipeline network information and establish a management system to avoid similar accidents from happening in the future.

5.1.2.4 Transparency Because there are 427 petrochemical pipelines in Kaohsiung that were laid many years ago, the central government should draw up competent and clear laws to manage petrochemical pipelines. The local government should take responsibility to ask all petrochemical companies to produce a transparent diagrammatical plan for all underground pipelines laid in Kaohsiung.

\subsection{Post-disaster restoration governance}

\subsubsection{Post-disaster process analyses}

After the Kaohsiung gas explosions, the residents, the central government should draw up competent and clear laws to manage petrochemical pipelines. The local government should take responsibility to ask all petrochemical companies 
5.2.1.1 Relief efforts [1] Many people, including high school students, volunteered during the post-disaster relief efforts to help with relief supplies distribution and offering of other services. Dozens of hotels around Kaohsiung offered temporary free lodging, laundry and washroom facilities for people who were left homeless after their houses were damaged by the blast.

Besides, the Ministry of National Defense deployed around 1,600 soldiers for the rescue operations, including 131 transport vehicles and other equipment.

So far, a total of NT $\$ 4.47$ billion worth of donations have been received from all the organizations, companies and individuals.

5.2.1.2 Restoration works [1] The restoration works are rapidly ongoing after the Kaohsiung gas explosions. The local government, companies and individuals have helped to reconstruct and repair the damaged houses of the residents along the roads.

The local government also applied a disaster relief claims plan, helping the victims ask for injury claim compensation, so that the victims could get reparation money to rebuild their houses and business.

The construction divisions of the city government have rebuilt the restoration work both day and night, including the repaving of the roads, reparation of the damaged sidewalks and replanting of trees along the road, and the rainwater drainage system under the roads.

The restoration works are still underway, and the main destroyed roads still only partly reconstructed, were opened to the public on 20 November 2014.

\subsubsection{Discussion and suggestions}

This paper examines post-disaster recovery activities as the following:

5.2.2.1 Accountability This paper finds that the local and central governments should take the most responsibility for disaster work recovery. Then, they should quickly implement the recovery plans and accelerate the recovery work to allow the residents return to their normal life and operate their businesses.

5.2.2.2 Participation As the recovery works are not so easily finished, the local and central governments should combine all the public and private resources to participate in recovery works effectively.

5.2.2.3 Predictability Because the explosions disaster had seriously hurt the lives of residents and the economic business, the recovery works are not just simple hardware work to be finished. The government also has to establish the multifaceted urban disasters management and economic development plans for safety, security, and a prosperous future life.

5.2.2.4 Transparency As the donations come from all the organizations, companies and individuals, the local government should be fully responsible for the best use of the money and effectively manage the expenditure and accounts, then open these to the public. Moreover, the auditing should be supervised by a fair management committee. 


\section{Conclusion and further works}

\subsection{Conclusion}

This paper reviews and examines the 2014 Kaohsiung gas explosions that seriously destroyed Kaohsiung city. It analyzes the source causes of leaking industrial underground propene pipelines, then identifies and assesses the pre-disaster explosion protection (risk assessment, mitigation preparedness, emergent plans) and post-disaster recovery (relief, rehabilitation, reconstruction, learning review) activities.

The Kaohsiung gas explosions were combined with following heavy rains and flooding along with a serious outbreak of dengue fever never seen before, so there were many composite difficult problems, it is so-called the normal accident. Besides, Kaohsiung is also is a heavy-industrial city, and the economic development and energy supply chains are vital to Kaohsiung and Taiwan. Therefore, this paper analyzes the issues by applying the approach of integrated governance with the key features of accountability, participation, predictability and transparency.

Finally, this research hopes to provide the central and local government with some important suggestions to deliver appropriate sustainable energy policies and reduce environmental risk.

\subsection{Further works}

Although the restoration works are still underway, and the main destroyed roads were partly reconstructed to be open to the public on 20 November 2014, many problems still need to be solved quickly. From the approach of integrated governance, this paper draws up the following suggestions for further work:

1. Clarify the authorities' responsibilities.

2. Argue the claims owing to the damages.

3. Manage the underground pipelines and conveying trucks.

4. Establish the overall restoration planning, including the environmental protection and economic development plans.

5. Provide the comfort of relief work carefully with much more patience.

6. Speed up and finish all the relative restoration works.

7. Open up transparent public participation.

8. Construct a new and separate special petrochemical industry zone.

9. Combine the restoration efforts with multi-faceted resources.

10. Learn the experiences and lessons from these disasters.

11. Prepare for the challenges of climate change and rebuild a resilient city.

12. Audit the restoration works and donations.

13. Derive synergy governance for environmental risk.

14. Develop a sustainable economy for the city.

15. Prepare for composite dangerous disasters in the near future. 


\section{References}

[1] Wikipedia, http://en.wikipedia.org/wiki/2014_Kaohsiung_gas_explosions

[2] Kaohsiung City Government, web site http://81khexp.kcg.gov.tw/

[3] Shaluf, I.M., An overview on disasters, Disaster Prevention and Management, Vol. 15 No. 5, pp. 687-703, 2007.

[4] Keeney, R, Understanding life-threatening risks. Risk Analysis, 15, pp. 627-37, 1995.

[5] Klein, K. and Petley, D.N., Risk assessment and management (Chapter 4). Environmental Hazards: Assessing risk and reducing disaster. Routledge: New York, pp. 50-71, 2009.

[6] Ahrens, J. and Rudolph, P.M. The Importance of Governance in Risk Reduction and Disaster Management, Journal of Contingencies and Crisis Management, 14(4): 207-220, 2006.

[7] Heinrich and Groh, Basic principles of explosion protection, September (Chapter 1). Explosion protection. Amsterdam; Boston: Elsevier/ Butterworth Heinemann, pp. 1-26, 2004

[8] Eziyi Offia Ibem, Challenges of disaster vulnerability reduction in Lagos Megacity Area, Nigeria, Disaster Prevention and Management: An International Journal, Vol. 20, Issue 1, pp. 27-40, 2011.

[9] John R. Labadie, Auditing of post-disaster recovery and reconstruction activities, Disaster Prevention and Management, Vol. 17, Issue 5, pp. 575-586, 2008.

[10] Robert Howes, After the disaster: drawing up the insurance claim, Aslib Proceedings, Vol. 55, Issue 3, pp. 181-187, 2003.

[11] Sara Kathleen Geale, The ethics of disaster management, Disaster Prevention and Management, Vol. 21, Issue 4, pp. 445-462, 2012.

[12] Tun Lin Moe Pairote Pathranarakul, An integrated approach to natural disaster management, Disaster Prevention and Management, Vol. 15, Issue 3, pp. 396-413, 2006.

[13] Bassam Baroudi and Randy R. Rapp, Stakeholder management in disaster restoration projects, International Journal of Disaster Resilience in the Built Environment, Vol. 5, Issue 2, pp. 182-193, 2014. 